\title{
Exergames: the role of ergonomics and design in helping to control childhood obesity through physical and functional exercise program
}

\author{
Marina Barros ${ }^{\mathrm{a}}$, André Neves ${ }^{\mathrm{a}}$, Walter Correia ${ }^{\mathrm{a}}$, Marcelo Soares ${ }^{\mathrm{a}}$ \\ ${ }^{a}$ Design Department, CAC, Universidade Federal de Pernambuco, Av. dos Reitores, S/N, Recife-PE, Brazil
}

\begin{abstract}
In the area of the design and physiotherapy, the using of virtual technologies for immersion of users are spreading. And this affirmation extends to several areas of knowledge. In games, the quote is, resources are being used to work cognitive skills, attention, memory, among other factors beside the children. Currently, at the expense of usability, low cost, virtual technologies of perception and interaction, as Nintendo Wii, X-Box 360, among others, arises therefore a new class of games called Exergames, which is the union of physical activity the game. This fact gives users the development of sensory and motor skills through virtual reality mechanisms suitable for certain needs. This literature review aimed to provide an overview of the current context of Exergames, especially in use for controlling childhood obesity, which is growing alarmingly, with some features, applications and possibilities for use at the design and other areas such as physiotherapy.
\end{abstract}

Keywords: Design, Ergonomics, Control Obesity

\section{Introduction}

According to the researcher [14] statistics show that the occurrence of childhood obesity is increasing every day around the world, and Brazil, the incidence has shown an alarming advance. In addition to possible medical complications of obesity, with the increasing call on the aesthetics, the implication of this self-esteem in children has also been a worrying factor.

Also according to the author, obese children may be part of those risk groups most likely to suffer various types of disorders in adulthood such as hypertension, respiratory diseases, heart disorders, diabetes, among others.

According to [10], in research with children and adolescents, nearly $98 \%$ of children who are considered "fat" does not exhibit any kind of hormonal disorder. Despite the genetic factor is of paramount importance, in general the major cause of childhood obesity is still physical inactivity and sedentary lifestyle.
The practice of any exercise requires an expenditure of energy that, when properly directed, can be easily used in weight control. It's no different for those exercises that can be done in front of a computer or a video game. In this sense, this research finca bases. It has been the main problem addressed in this, childhood obesity. By proposing to address the problem through the application of design in the use of digital games, opens a second front of problems, more specific process of design, production and use of digital games based on player movement.

This article aims to present the state of the art project developed in the master in the design area, demonstrating the importance of engaging with the methodological design issues that are solvable using techniques to create digital games based exercise program. 


\section{State of the art}

According to project director of Exergame Unlocked, Barbara Chamberlin, in order to deconstruct the image created from digital games that encourage sedentary practice in public child, several gaming companies have been working in the digital design of a new class of games digital take based on the physical movement of the players, currently known as exergames. Supported on different technological bases, such games have been released by manufacturers of weight on the world stage, such as Sony and Nintendo [3].

Some of these games have the explicit purpose of bringing the digital game player to change their stance sedentary and aerobic physical activities such as games Wii Fitness package of Nintendo or Sony's EyeToy Kinetic.

However, as [13] despite its proven efficiency and high standard of quality, the games are still bearing exercise as the main factor limiting its wide popularity, the cost of the equipment involved and specificity that have very limited installed base, and many times they do not have a proper monitoring of health professionals.

\subsection{Childhood Obesity}

Obesity is a chronic disease which is accompanied by multiple complications, characterized by excessive accumulation of body fat to such an extent that compromises the health of the individual, whether child or adult and elderly.

It can be seen as the result of taking more energy than necessary. This excessive consumption associated with sedentary habits have their origin in various stages of life and is influenced by familial, cultural, psychological, etc.. For this reason, there is a clear trend among members of a family having a body mass index (BMI) similar.

Table 1 - Reference of BMI with the degree of obesity.

\begin{tabular}{l|l}
\hline Category & BMI \\
\hline marasmus & Less than 16,5 \\
\hline Underweight & from 16,5 to 18,5 \\
\hline Healthy & from 18,5 to 25 \\
\hline Overweight & from 25 to 30 \\
\hline Obesity & from 30 to 35 \\
\hline Obesity clinic & from 35 to 40 \\
\hline Morbid obesity Source: Adapted from [11]
\end{tabular}

The body mass index is currently the main factor for measuring obesity. BMI is calculated from the relationship between individual body weight and your height squared (weight $/$ height ${ }^{2}$ ). The result of this relationship should be observed according to the Table 1.

For children, does not apply directly to this table, the National Center for Health Statistics (NCHS) indicates to the age of seven to nine years in the Table 2 .

Table 2 - Reference BMI for children.

\begin{tabular}{l|l|l}
\hline Age & Gender & BMI normal \\
\hline 7 to 9 years old & Male & from 14 to 24 \\
\hline 7 to 9 years old & Feminine & from 13 to 22 \\
\hline \multicolumn{2}{l}{ Source: Adapted from [11] }
\end{tabular}

The age group chosen for this study were children from seven to nine years of age by the fact that, according to authors such as [9] and [15], this period of childhood, the child acquires greater autonomy for a series issues of everyday life, how to choose clothes that will wear, choose their own food and define the activities that will hold, such as watching television, playing digital games or playing with friends on the playground or the building in his backyard. Thus, as an important moment for the encouragement of healthy activities.

As mentioned in the abstract and the title, this article aims to present a state of the art for the issue raised in it, not coming at this point in detail about the application with the selected users.

\subsection{Exergames}

There is no way to talk about games without mentioning today in virtual reality. This type of "reality" came in 1950, with flight simulators for testing, however, the potential of this tool for training, according to [12] expanded the application of technology for various fields such as medicine, Engineering, Architecture, Psychology and Education. The interface of virtual reality technology is responsible for this set of tools used in education as it is able to provide greater user interaction, in which the ability to view different environments along with other sense organs, such as hearing and touch, increases the sensitivity of the user. This is not a simple adaptation to new technologies: the coupling with computers should be understood by cognitive links that can be produced such as the development of strategic thinking, reasoning and perception [4]. 
After several years of research on games, a new class of digital games based on the physical movement of the players has been developed by different manufacturers in the segment of digital games. Known as "exergames" or "activegames" have as a principle the use of new forms of interaction between player and game.

The exergames cause the player to work a series of aerobic exercise as a way to respond to events triggered in the game. Some exergames are used explicitly to exercise and others have an indirect focus on exercise, are games that have more focus on entertainment and social integration. Regardless of the focus of exergame, the player will experience the benefits of physical activity in any way. In fact, the games that are just "away" or "mask" that focus that are most successful with players of digital games [3].

The production of exergames had as March, the launch of the game "Dance Dance Revolution" (DDR) from Konami. The game mechanics are simple, the central idea is to mimic the movements of a character who dances on the computer screen. Players step onto a mat with sensors that tell the game where the player stepped on. Recently, Sony released the EyeToy, an accessory for the PlayStation 2 as the main component that has a camcorder that reads the image of the player and allows it to interact with game objects. The game EyeToy Kinetic launched in partnership with Nike, the sports sector company, is based on, or help teach players to practice martial arts, as can be seen in the Figure 1.

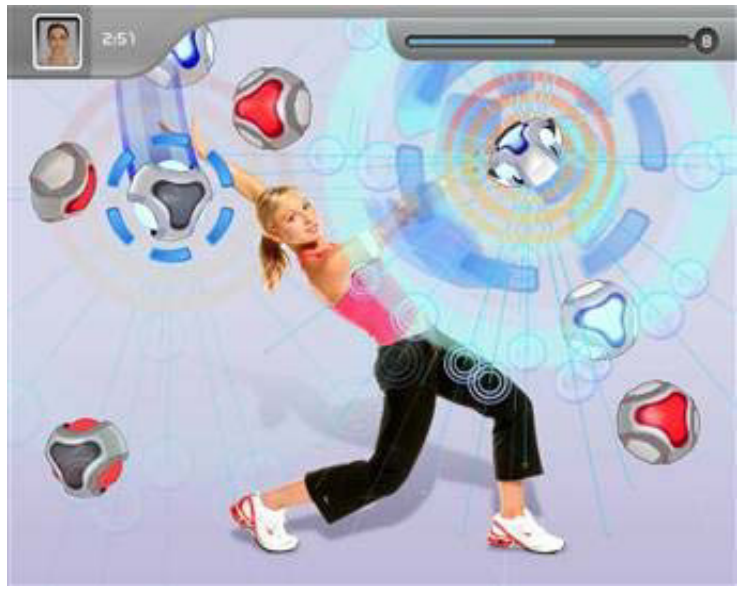

Figure 1 - Example of interactive game for the PlayStation 2. Source: [7]

Some of the games developed for Nintendo WII simulate traditional games such as golf or tennis, where the control takes the form of a racket or a bat.
The webcam games are focused primarily on the casual gamer, and are strongly oriented to entertainment. Despite the great potential, since it is a new technology, little has been explored in the market there is a successful product.

Based on these kind of games, a taxonomy of exergames was proposed by [8], Subdividing them into four categories:

- (i) Effort and no-effort involving the interface of the game. All interface changes exergames body movements in input data, ie, it is necessary to move the joystick up or moving platforms or mats to the system reconstruct the movements;

- (ii) Competitive and Non-competitive: in relationship (the first) with opponents who may be one or more (multiplayer) or the computer itself, in the second, the notion of opponent does not exist;

- (iii) Non-Parallel and Parallel, linking up with the idea of opponent, as this relates to collaboration, that is, users playing together in the same team or group with common goals and tasks, and;

- (iv) Anti-Object - featuring the game in which the user tries to control an opponent, as in a fight, for example, unlike the object, which, as its name suggests, the user tries to control an object.

An important and inherent to games and can not be overlooked is the characteristic playful. According to [1], the lack of playfulness or no influence on the motivation for the game, so one can not ignore the exergame game character. However, it should provide interface features of exercise, encouraging physical exercise. Balancing this should be considered in the design and development of these.

\subsection{Physiological aspects related to the use of Exergames}

According to [2] studied and classified as a group of studies investigated the physiological caloric expenditure exergames promoted by many, especially in children and young people of school age. Showed an increase in the level of physical activity and heart rate in relation to sedentary video game.

The same results were found by [5], who used two samples of individuals with different ages: a group of 22 children (12 years) and another group with 20 adults (34 years). With increasing amount of muscle involved in the game, the higher the energy 
expenditure. The authors analyzed the contribution of the upper and found differences statistically significant between exergames and sedentary games.

However, when comparing these data suggested daily calorie expenditure by the American College of Sports Medicine, the findings were only preliminary and require more careful research that relates exergames with physical activities and sports.

Another important aspect in the groups analyzed by the authors of the experiments was the lack of research on the development of physical capabilities of each user, and that may be useful in the actual development of games in the area. The works that were found were limited to investigate only aerobic fitness, so a field also indicate that very little explored.

\section{Conclusions}

The problem of childhood obesity is now an issue of epidemic proportions globally, with serious consequences for public health, and is considered by who as a major factor in increased risk of serious diseases such as childhood diabetes and hypertension, and certain types of cancer. The inactivity caused by various factors such as overexposure to the front of the television, lack of exercise, and others show up as often being a factor for obesity.

Advances in Information and Communication Technology, combined with problems mentioned above, contributed to the emergence of this new class of games specifically designed to entertain through a less sedentary physical activity. In them, the interface is designed to use human movement as input data, with the intention to increase caloric expenditure and interactivity, so that there is less physical inactivity by its users.

Assuming that computers with webcam are increasingly common in the domestic, work in the area of game development that help control obesity and other diseases, should be thought more and more, so they can spread more easily exergames, especially in schools and homes of families with lower power consumption.

\section{References}

[1] BARBOSA, M.C.S. (1997). Jogo, brinquedo, brincadeira e educação. Educ. Soc., 18, 398-404.

[2] GRAVES, L.; STRATTON, G.; RIDGERS, N.D. e CABLE N.T. (2007). Energy expenditure in adolescents playing new generation computer games. Br. Med. J., 335, 22-29.

[3] HUNICKE, R., LEBLANC, M. e ZUBEK, R. (2009) MDA: A Formal Approach to Game Design and Game Research. Design Issues, MIT Press. 4(9) p. 234 - 246.

[4] KASTRUP, V. (2004). A aprendizagem da atenção na cognição inventiva. Psicol. Soc., 16, 7-16.

[5] LANNINGHAM-FOSTER, L.; Foster, R.C.; MCCRADY, S.K.; JENSEN, T.B.; MITRE, N. e LEVINE, J.A. (2009). Activity-promoting video games and increased energy expenditure. J. Pediatrics, 154, 819-823.

[6] LEBLANC, M. (2004) "Game Design and Tuning. In: Workshop Materials Game Developers Conference. Disponível em: http://8kindsoffun.com/gdc04. Acessado em $13 / 2 / 2010$

[7] MSNBC (2006) Can a PlayStation replace a treadmill? Examples of EyeToy: Kinetic screenshot. Disponível em www.msnbc.msn.com/id/10075320/. Acessado em 15/2/2010

[8] MULLER, F.F.; GIBBS, M.R. e VETERE, F. (2008). Taxonomy of Exertion Games. Em: Proceedings of OZCHI, Australasian Computer Human Interaction Conference. Melbourne, Austrália. p. 263-266.

[9] PIAGET, J. e INHELDER, B. (2006) A psicologia da criança, $2^{\text {a }}$ Ed. Rio de Janeiro: Difel.

[10]REILLY, J. J. (2006) Obesity in childhood and adolescence: evidence based clinical and public health perspectives, Postgrad. Med. J., July 1, 82(969): 429 - 437.

[11]REYNOLDS， K. D. e SPRUIJT-METZ， D. (2006) Translational research in childhood obesity prevention, Eval Health Prof, June 1; 29(2): 219 - 245.

[12]ROSENBAUM, E.; KLOPFER, E. e PERRY, J. (2007). On Location Learning: Authentic Applied

[13] SALEN, K. e ZIMMERMAN, E. (2004) Rules of Play: Game Design Fundamentals. Cambridge MA, The MIT Press.

[14] SENNINGER, F. (2009) Obesidade Infantil: Como Fazer a Criança Emagrecer Suavemente. São Paulo, Ed. Vozes.

[15] VYGOTSKY, L. S. (2007) A formação social da mente: o desenvolvimento dos processos psicológicos superiores, $7^{\mathrm{a}} \mathrm{Ed}$ São Paulo: Martins Fontes. 